\title{
HEART
}

Editorial

\section{Heart: the change of title}

This century has been marked by a rate of change that is arguably higher than at any time in history. Publishing is no exception and for a specialist journal to survive it must adapt to changes in the needs of readers, subscribers, and authors in the increasingly international world of cardiology. Such adaptations, however, must be based on projections of the future. It is often said that he who hesitates is lost: however, as Thurber pointed out, sometimes he who hesitates is saved. So not only must the future be predicted but the right time for change must be selected.

The British Cardiac Society with its partner the BMJ Publishing Group have attempted to predict the future. A likely scenario is that there will be fewer journals and a clearer division into those that are national and those that are supranational (international). National journals will often not be published in English and will concentrate on politics, news, education, and audit for local readers. International journals will be in English and in addition to postgraduate education and review of practice in the specialty they will publish primary research work in the specialty area and the content will be aimed at a wide international audience. The British Cardiac Society has always seen the British Heart fournal as having a broad international role, which has always been fostered by previous editors. The perception that the British Heart fournal is international may not be universal, however. Much of the work published in the British Heart fournal in the last decade has come from authors within the United Kingdom. Efforts to correct this imbalance over the past two years have seen a gratifying rise in submissions from outside the United Kingdom. In 1994, 56\% of submissions came from outside the United Kingdom. Since 1992, submissions from mainland Europe have risen by $72 \%$. This being so, the time seemed right to the BMJ Publishing Group, British Cardiac Society Council, and a substantial majority of Society members, who expressed their view in a referendum, for the British Heart fournal to revert to the title of Heart.

In many ways this is a reversion rather than a change of title. The history of how the British Heart fournal evolved from its ancestor Heart in the 1930s is a fascinating study of the interplay of personalities and interests within British cardiology of the time and is reviewed by the archivist of the British Cardiac Society on page 3. At the moment it is sufficient to say that Heart was the forerunner of the British Heart fournal and that from January 1996 we will revert to the title Heart.

This change aims to underline our commitment to be an international, English language, European based journal of cardiology. Clinical cardiology will remain the central theme: nonetheless, we all recognise that advances in basic science are entering the clinical domain very rapidly. Therefore, many papers will deal with subjects such as genetics and molecular biology in their human and clinical context.

The change of name will also be accompanied by a major expansion in the number of members of the International Advisory Board from outside the United Kingdom-particularly mainland Europe. We hope that this will help us to attract more submissions from outside the United Kingdom. Much, however, will stay the same-we are not launching a totally new Journal. The cover will not substantially alter and will emphasise that Heart is the official journal of the British Cardiac Society. The British Cardiac Society will continue to circulate its own official Newsletter to members. This will contain all the news of purely national interest that formerly appeared in the Journal. The volume numbering of Heart will continue from that of the British Heart fournal-thus volume 75 will be the first to carry the title Heart.

M J DAVIES

Editor, Heart

\section{Heart: what we wish to publish}

We and our authors find it helpful to categorise submitted papers. So that space in the journal is used effectively we have laid down guidelines on length for each of our categories. Succinct writing not only increases the chances of an article being read and understood but also makes space available for other work to be reported.

We endeavour to adhere to the convention that all authors should have had an intellectual input to a paper and be responsible for its content. We ask you to bear this in mind. For example the intellectual content of a case report seldom merits more than three authors.

The chances of an article being read and cited, an outcome that serves the interests of both the author and the journal, are enhanced by the use of structured abstracts. These ensure that data can be retrieved easily and comprehensively by computerised literature searches. Remember that only the first 250 words of a structured abstract will be captured on the electronic databases. A comprehensive guide to the writing of structured abstracts has been published in the fournal of the American Medical Association, ${ }^{1}$ we are reprinting this on pages 106-8. In addition, because computerised reference databases are now so widely available we no longer see that it is the role of a journal to provide exhaustive reference lists-40 key references should usually suffice for an original paper or review. The main categories of papers that will be published in Heart are shown overleaf. 


\section{Original scientific papers}

Authors submitting papers reporting original data (for example, controlled trials and intervention studies) should not exceed a limit of 4000 words, six figures or tables, and 40 references, and should provide a structured abstract of up to 250 words. If after removing redundancy and repetition your article exceeds these limits please consider whether you are not better served by writing two separate articles: but bear in mind the need to avoid duplicate publication. The editors may choose to use a heading for an original scientific paper such as technique, technology, or measurement.

\section{Reviews, editorials, and viewpoints}

- Reviews are balanced accounts of all aspects of a particular subject including the pros and cons of any contentious or uncertain aspect. They must not be more than 3000 words long with up to 40 references.

- Editorials are shorter, 1500 words and 16 references, and give the judgement of the writer based on published data.

- Viewpoints are the same length as editorials but are designed to let the author speculate on the whys and wherefores of any subject, procedure, or treatment.

The editors of Heart commission nearly all the editorials, viewpoints, and reviews published in the journal. Before spontaneously writing us an editorial or review, please first consult us about your ideas. This will avoid the disappointment of finding that we have already commissioned an article on a similar topic from someone else.

\section{Case reports}

We wish to publish case reports which illustrate and discuss particular points that are relevant to clinical practice. Rarity is not a necessary component. Case reports should have no more than three authors and be up to 1500 words long with up to 10 references and three figures and/or tables. You should supply a summary (up to 150 words) of the main message of the article.

\section{Case studies}

We are willing to consider case studies that more fully discuss the concepts of a particular disease. Such extended reports may be of a small series of cases and can have more references (25 maximum) and illustrations. When submitting a case study please indicate why the disease warrants extended discussion or description. Case studies too require a 150 word summary.

\section{Short cases in cardiology}

Ideally these should fit less than one journal page-up to 600 words (with no more than two figures, five references, and three authors). Many papers in this category come to us as longer case reports, from which they differ mainly in having no summary and a much shorter discussion. The object of having this category for the journal is to report as many interesting and clinically helpful cases as possible. These short reports, particularly those that are well illustrated, are popular with readers. This is the category best suited to your rarities.

\section{Images in cardiology}

This category is intended for beautiful, striking, or rare images or pictures-be they electrocardiograms, echocardiograms, scans, $x$ rays, or pathology specimens. They should have no more than three authors and the message of the picture may be amplified in a 250 word legend, without references. The illustration may be in colour if this is required.

\section{Letters to the editor}

We welcome letters commenting on papers published in the journal in the previous six months. Readers are more likely to take a lively interest in a letter to the editor if it appears soon after the article to which it refers. So please fax (+44 171388 0323) or e-mail (100536.2733@compuserve.com) your letter as soon as possible. Always follow this up by sending us the original by post. All authors must sign the letter, which should not be more than 600 words and six references in length and must be double spaced. It may contain short tables or a small figure. Topics not related to papers published earlier in the journal may be introduced as a letter: letters reporting original data may be sent for peer review.

1 Instructions for preparing abstracts. $\mathcal{F A M A} 1995 ; 273: 29-31$. 